\title{
Examining Scientific Literacy through New Media
}

\author{
Xiaoqing Gu ${ }^{1 *}$, Chunli Wang ${ }^{2}$, Lin Lin ${ }^{3}$ \\ ${ }^{1}$ East China Normal University, CHINA \\ 2 Henan Normal University, CHINA \\ ${ }^{3}$ University of North Texas, USA
}

Received 10 February 2019 - Revised 29 May 2019 - Accepted 10 June 2019

\begin{abstract}
This study aims to evaluate the impact of new media on scientific literacy. Content analysis with a coding scheme was performed on 42 filtered websites and 20 microblogs to analyze the role of new media in disseminating scientific knowledge. The results showed that the quality of science-oriented websites was higher than that of microblogs. Although both types of new media include valid and accurate information, concerns have been expressed regarding the lack of in-depth analysis of scientific knowledge. In addition, a questionnaire was administered to 1,870 sampled college students to determine their scientific literacy levels. According to the results, the use of science-oriented microblogs does not produce a statistical difference, whereas students who use science-oriented websites have higher scientific literacy level than the non-users. Furthermore, students' identification ability for scientific information from new media is significantly correlated with their scientific literacy. Students' education, major, and identification ability contributed to their scientific literacy. Suggestions about how to improve the quality of science-oriented new media and how to develop students' scientific literacy through new media have been discussed.
\end{abstract}

Keywords: new media, science-oriented websites, science-oriented microblogs, scientific literacy, scientific knowledge

\section{INTRODUCTION}

Scientific literacy and economic growth have been working together (Hanushek \& Woessman, 2016). An advanced economy needs individuals with scientific and technological skills. In turn, scientific literacy boosts economic competitiveness, increases the employment rate, and contributes to a high standard of living. Improving scientific literacy of the general public also has a significant positive impact on the well-being of individuals and the quality of public decision-making and administration (Bauer, 2009). Thus, how to promote and enhance national public scientific literacy cannot be ignored and should be explored.

Compared with traditional media like TV and newspaper, new media represent diverse changes in aspects of media production, distribution, and uses, which include, but not limited to, those digital, hypertextual, interactive and networked communication formats (Lister et al., 2009). National Science Board (2014) indicated that new media is becoming an important source for specific scientific issues. Impey (2013) showed that US non-science major students' scientific literacy only gained $10 \%$ by attending science classes, and the influence of new media should not be ignored in future study. However, there are also research showing that new media, particularly social media, are playing a controversial role in increasing public engagement for scientific knowledge. One of the primary reasons for this controversial role is that everyone can disseminate scientific knowledge without the filter of a traditional gatekeeper (Brossard, 2013; Laberge, 2016). Consequently, knowledge disseminated through new media is not always accurate or correct (Nisbet et al., 2002). Meanwhile, scientific knowledge is typically perceived as anticommon sense (Brossard, 2013), thereby making its dissemination a complex process. In particular, higher-level and complex scientific knowledge is difficult to disseminate through the fragmented and non-integrated manner of new media.

(C) 2019 by the authors; licensee Modestum Ltd., UK. This article is an open access article distributed under the terms and conditions of the Creative Commons Attribution License (http://creativecommons.org/licenses/by/4.0/). \xqgu@ses.ecnu.edu.cn guxqecnu@gmail.com (*Correspondence) \ clwang66@163.com $₫$ Lin.Lin@unt.edu 


\section{Contribution of this paper to the literature}

- Science-oriented new media has become frequently used channels for scientific knowledge among college students. As two representative types, science-oriented websites had higher quality than science-oriented microblogs.

- Students who obtained scientific knowledge from science-oriented websites had significantly higher scientific literacy level than the non-users. However, whether students used science-oriented microblogs or not did not bring such difference.

- Students' identification ability for science-oriented new media was important. Together with their education and major, identification ability was correlated with students' scientific literacy.

What is the exact situation that surrounds scientific communication in this age of new media? What do we, as science educators, need to do? This study aims to evaluate the impact of new media on communicating scientific information by examining the quality of those science-oriented new media. In addition, the study also examines the scientific literacy level of the general public exposed to such new media to find the relationships between the levels of scientific knowledge and the quality of those new media that aim to dissemination of scientific knowledge. A time existed when mass media were the only information sources available to the general public about scientific discoveries, controversies, events, and the works of scientists. A positive relationship developed between mass media and public scientific knowledge (Nisbet et al., 2002). Accordingly, educational researchers have used mass media as the starting point for implementing and improving scientific literacy (Brossard \& Shanahan, 2006). However, whether this point could also be verified in new media age is uncertain. The findings of this study help to build a foundation for further investigations into the relationships between scientific literacy and new media. They may also provide a baseline for future research and for implications of interventions that use new media to enhance the scientific literacy levels of the public, particularly the college students.

\section{LITERATURE REVIEW}

\section{Research on Scientific Literacy}

The scientific literacy of the public is important because of its benefits and close relationship to the national economy, the field of science itself, science policy making, and many aspects of a society; it also helps enhance people's lives in today's science-and-technology-dominated society (Laugksch, 2000; Thomas \& Durant, 1987).

Many researchers and organizations have offered their definitions of scientific literacy. This term originated from 1950s and was first used in a publication about developing scientific literacy among young American people (Hurd, 1958). Different definitions have been proposed since then and the one offered by Miller (1983, 2004) has been influential. He defined scientific literacy from three dimensions: (1) understanding of the science norms and methods, (2) understanding core terms and concepts in science, and (3) understanding the impact of science and technology on society. This definition and correspondent measurements have been used in United States and other countries since 1980s. In addition, scientific literacy is used interchangeably with "Public Understanding of Science" (PUS) which is frequently used in Britain (Laugksch, 2000). Rennie (2005) also proposed a definition used by Swedish national school curricula of science, which is defined as "knowing science as a way of thinking, finding, organizing and using information to make decisions" (p. 10). State Council of the People's Republic of China (2006) regarded scientific literacy as the ability to understand necessary knowledge in science and technology, to know basic scientific methods, to think scientifically, to promote the scientific spirit, and to use the aforementioned skills to make decisions regarding individual's life and to participate in public affairs that involve science and technology. In all, scientific literacy implied individual's ability or skills related with science issues such as science concepts, methods, and attitude.

There are increasing concerns about public's scientific literacy level. Three decades have passed since Thomas and Durant (1987) raised the question "why should we promote Public Understanding of Science?" The notion was referred in the field as PUS at a time when the attitude of the general public toward science and technology was not sufficiently positive. Miller $(1983,2004)$ adopted scientific literacy level to describe the degree of individuals' scientific literacy. He has conducted the nation-wide research on US adults' scientific literacy levels, and found only a small percentage of US adults had knowledge about basic science concepts. Impey (2013) studied American college students' scientific literacy level from three aspects: scientific knowledge, science attitude, and pseudoscience beliefs. Each aspect was assessed by related statements and then coded on a Likert scale. According to the survey with 11,000 undergraduate students at the University of Arizona who were near their graduation, the results showed the scientific literacy level of college students did not improve significantly in the past twenty years. All these study results indicate that to enhance scientific literacy level remains a challenging task. 


\section{New Media and Scientific Literacy}

Traditional efforts in science communication include scientists communicating to a widespread audience, and science writers publishing in newspapers and magazines, broadcasting through mass media (i.e., radio and television), and through popular books. An increasing number of science museums and science centers are holding exhibitions and promoting science through various activities and organized festivals. These traditional efforts are growing in scope and taking innovative forms through new information and communication technologies (Brossard \& Shanahan, 2006). The new information and communication technologies have formed a major avenue to communicate with the public regarding knowledge of science and technology (Rundgren, Rundgren, Tseng, Lin, \& Chang, 2012).

As new media created an important context in which the public can develop their scientific literacy, it is critical to investigate the quality of the new media in regards to scientific knowledge dissemination. Pariser (2012) revealed the importance of the information authority on Internet, especially for information on relatively new topics that people are unfamiliar with. Because of the social nature of Web 2.0 which allows people to produce information by themselves, the debate about roles and functions of emerging technologies in science communication is on-going and changing (Aral \& Walker, 2012). For example, the communication effect for a scientific phenomenon may be influenced by number of "likes" and "followers", and by different attitudes contained in the comments. Although some studies have examined the new media in general, research that systematically reviews and studies scienceoriented new media and their relationships with scientific literacy is limited (Fauville et al., 2015; Harris, 2007).

Ability to use scientific information critically from new media is such an important competence for anyone in today's society. Unlike mainstream science communication with mass media, where scientific knowledge is translated by a professional in the media environment, scientific knowledge is not only directly communicated to an unspecialized "lay" audience, but also commented upon, discussed, debated, and produced by the unspecialized public (Brossard, 2013; Brossard \& Scheufele, 2013). This evolution has significantly affected public perceptions of new scientific developments and general understanding of science (Anderson, Brossard, Scheufele, Xenos, \& Ladwig, 2014; Brossard, 2012; Brossard \& Scheufele, 2013; Liang et al., 2014). As indicated by Jarman and McClune (2007) and Zimmerman et al. (2001), being exposed to a new media environment that is incorporated with biased information, the public should be able to discern information critically and determine its quality based on its sources and the manner in which it was produced. However, the ability to distinguish between reliable and unreliable scientific information is currently undocumented among students (Impey, 2013).

\section{Research Questions}

As situation is changing primarily due to the rapid evolution of the Internet and the abundance of social media (Peters, Dunwoody, Allgaier, Lo, \& Brossard, 2014), the public is turning to online environments such that the Internet and social media as important sources of scientific information and the works of scientists (Brossard, 2013). This study aims to study the influence of new media on scientific literacy of their users. The following questions are to be focused:

(1) What is the quality of science-oriented websites and science-oriented microblogs in new media?

(2) How does scientific literacy relate to the uses of science-oriented new media? Three sub-questions were proposed to help answer the second research question:

- What is the students' scientific literacy level?

- What are the features of students' science-oriented new media uses?

- What is the relationship between new media uses and students' scientific literacy?

The relevance of the two questions lies in that the first one targets the quality of scientific information from new media, which could provide a context explanation for the relationship between new media and scientific literacy.

\section{METHODOLOGY}

A mixed method was adopted in this study to determine the current situation of social media in disseminating scientific knowledge and the scientific literacy levels of new media users. In the first part, a content analysis was applied to 42 Chinese filtered science-oriented websites and 20 relevant Chinese microblogs. In the second part, a questionnaire was administered to 1,870 Chinese college students who were sampled using a convenient sampling method. These students are typical avid users of social media, and they come from administrative regions of the country. 


\section{Measures of the Quality of Science-oriented New Media}

\section{Samples}

This study chose science-oriented websites and microblogs as the representative of new media because they are listed by American Association for the Advancement of Science (AAAS, 2016) as typical platforms for communicating scientific knowledge. Websites usually present information from owner's perspectives, while social media like microblog serves as real-time and engaging channels for scientific knowledge.

Over 150 science-oriented websites were originally collected through web search and snowball links. They were then filtered down to 54 sites by eliminating sites using the following criteria: 1) sites with wrong domain names and 2) sites without updates for at least 1 year. After further examination, 12 websites were removed for various reasons from inappropriate site contents to excessive publicity. Finally, 42 websites were selected for the study and they were classified into two categories: comprehensive and domain-specific science websites.

In addition, 10 institutional and 10 personal microblogs were sampled by using keywords like "science", "scientific" to search in Sina Microblog (the Chinese version of Twitter), The search results were filtered according to the criterion of having 500 or more followers. Moreover, each microblog was confirmed whether the topic was about science by reviewing its high frequency words extracted by ICTCLAS (Institute of Computing Technology, Chinese Lexical Analysis System).

\section{Coding}

A coding scheme that assessed the quality of science-oriented websites was developed by adopting the specific evaluation system for science websites entitled Evaluating Science WWW Resources (North Carolina State University's Science Education Research in Visual Instructional Technologies [SERVIT] Group, 1999), while exerting efforts to combine and incorporate the works of Smith (1997) and Harris (2007).

Table 1 illustrated the coding scheme with 6 first-level dimensions and 16 second-level dimensions. The first two dimensions, "Intended audience" and "Website organizers", were proposed by Harris (1997). They were used here as it could provide evaluation of each website's background. "Intended audience" meant for whom the information was designed for. "Website organizers" represented whether the owner was institution or individual, non-profit or profit. The dimension of "scope of scientific knowledge" developed by Smith (1997) was adapted as this was an important indicator that was missing in Evaluating Science WWW Resources. It focused on the breadth and depth of the scientific knowledge provided. The last three dimensions in Table 1 were adapted from the studies of SERVIR Group (1999) and Smith (1997). These dimensions were mentioned in the two studies. "Science content issues" referred to the accuracy, authority, update, and uniqueness of the resource. "Workability" could be assessed by four aspects: ease of browsing, readability, search engine, external links. "Interactivity" was proposed to describe the interactive feature of new media. The second-level dimensions in Table 1 were collected from the three aforementioned evaluation systems and repetitive indicators were deleted. Notably, the second-level dimensions of "accuracy" and "authority" had third-level dimensions. For the first three dimensions, multiple choice items were designed, with a score of 1 to 3 for different options. For the last three dimensions, "true or false" items were designed, where "true" was scored as " 1 " and "false" was scored as " 0 ." The exception to the scaling was the number of comments in the "interactivity" dimension, which was calculated by the average number of comments for the latest 10 articles. 
Table 1. Coding scheme for science-oriented websites

\begin{tabular}{|c|c|c|c|}
\hline \multirow{3}{*}{$\begin{array}{l}\text { First-level dimension } \\
\text { Intended audience } \\
\text { (Harris, 2007) }\end{array}$} & \multirow{2}{*}{$\begin{array}{l}\text { Second-level dimension } \\
\text { Age group }\end{array}$} & \multicolumn{2}{|c|}{ Third-level dimension Items Type } \\
\hline & & - & Multiple choice item (1. Children 2. Adults) \\
\hline & User level & - & Multiple choice item (1. Specialist 2. Public) \\
\hline \multirow{2}{*}{$\begin{array}{l}\text { Websites organizer } \\
\text { (Harris, 2007) }\end{array}$} & Organizers' background & - & $\begin{array}{l}\text { Multiple choice item (1. Institution } 2 . \\
\text { Individual) }\end{array}$ \\
\hline & Organizers' mechanism & - & Multiple choice item (1. Non-profit 2. Profit) \\
\hline \multirow{2}{*}{$\begin{array}{l}\text { Scope of scientific } \\
\text { knowledge } \\
\text { (Smith, 1997) }\end{array}$} & Breadth & - & $\begin{array}{l}\text { Multiple choice item (1. Specialized } 2 . \\
\text { Comprehensive) }\end{array}$ \\
\hline & Depth & - & $\begin{array}{l}\text { Multiple choice item (1. Brief description } 2 . \\
\text { Explanation 3. Expansion) }\end{array}$ \\
\hline \multirow{7}{*}{$\begin{array}{l}\text { Science content issues } \\
\text { (SERVIT Group, 1999; Smith, } \\
\text { 1997) }\end{array}$} & & $\begin{array}{l}\text { Providing information } \\
\text { source }\end{array}$ & Yes/No item \\
\hline & Accuracy & $\begin{array}{l}\text { Providing review } \\
\text { mechanism }\end{array}$ & Yes/No item \\
\hline & & Content Bias & Yes/No item \\
\hline & & Academic Background & Yes/No item \\
\hline & Authority & $\begin{array}{l}\text { Providing author's } \\
\text { contact information }\end{array}$ & Yes/No item \\
\hline & Regular update & - & Yes/No item \\
\hline & Content uniqueness & - & Yes/No item \\
\hline \multirow{4}{*}{$\begin{array}{l}\text { Workability } \\
\text { (SERVIT Group, 1999; Smith, } \\
\text { 1997) }\end{array}$} & Ease of browsing & - & Yes/No item \\
\hline & Readability & - & Yes/No item \\
\hline & Search engine & - & Yes/No item \\
\hline & External links & - & Yes/No item \\
\hline \multirow[b]{2}{*}{$\begin{array}{l}\text { Interactivity (SERVIT Group, } \\
\text { 1999; Smith, 1997) }\end{array}$} & Comment section & - & Yes/No item \\
\hline & Comment number & - & $\begin{array}{l}\text { Average comments number for latest } 10 \\
\text { articles }\end{array}$ \\
\hline
\end{tabular}

The coding scheme for science-oriented microblogs was slightly modified according to the nature of microblogs. The "workability" dimension was removed because all the samples were collected from the Sina microblog website with the same type of technical support. The comment section in the "interactivity" dimension was replaced with the number of followers, which represented the social influence of microblogs.

The selected science-oriented websites and microblogs were coded by four research assistants using the aforementioned coding scheme. All of them were second year graduate students in learning technology major. Before this process, the assistants were trained for approximately $4 \mathrm{~h}$ to understand the coding scheme and to become familiar with the coding process. Eventually, they were able to conduct coding in two assisted pairs. Interrater agreement between the two pairs were $91 \%$.

\section{Measure of Students' Scientific Literacy Level and their Science-oriented New Media Use}

\section{Instrument}

The instrument used to measure scientific literacy was mainly adopted from Miller $(1983,2004)$. This instrument begins by identifying the major facets of scientific literacy, such as facts, concepts, scientific methods/processes, and attitude toward science, which are described in slightly different ways in the literature, but have most commonly been referred to as dimensions in measuring scientific literacy (AAAS, 1993; Fauville et al., 2015; Miller 1983; National Research Council 1996; Rubba \& Andersen, 1978). The subdimensions and their associated items were mainly derived from the survey of Miller $(1983,2004)$, which has been used for 20 years to assess knowledge of science and technology in the US (National Science Board, 2016). Several science topics, which were intended to test the understanding of science concepts, were incorporated based on the results of how frequently they were used in web searches for science topics, e.g., "PM2.5," to replace items that might be outdated. Items for the subdimension "rejection of superstition" were appropriate for the Chinese culture, which included issues such as fortune telling sticks and dream interpretations. Items for the (fifth) subdimension of "scientific attitude" were adopted from the work of Gauld (1982) and Fives, Huebner, Birnbaum, and Nicolich (2014), in which scientific attitude was described as the capability to engage in public scientific activities. Eventually, 3 dimensions and 5 subdimensions with 23 items were developed and applied to the measure. A total score was generated by following standard procedures, in which the maximum score was 100 points and each subdimension weighted 20 points as indicated in Table 2. 
Table 2. Instrument of scientific literacy measurement

\begin{tabular}{|c|c|c|c|}
\hline Dimension & Sub-dimension & Item type & Item example \\
\hline \multirow{2}{*}{$\begin{array}{l}\text { Basic scientific } \\
\text { constructs }\end{array}$} & $\begin{array}{l}\text { Understanding of } \\
\text { scientific concepts }\end{array}$ & $\begin{array}{l}4 \text { multiple choice items on GM, Molecule, PM2.5, } \\
\text { Nanometer }\end{array}$ & $\begin{array}{l}\text { In the following four options, which } \\
\text { one is the right description of GM? }\end{array}$ \\
\hline & $\begin{array}{l}\text { Understanding of } \\
\text { scientific viewpoints }\end{array}$ & $\begin{array}{l}10 \text { True/False items on Velocity of light, } \\
\text { Antibiotics function, Radiation phenomenon, etc. }\end{array}$ & $\begin{array}{l}\text { Light travels faster than sound, true } \\
\text { or false? }\end{array}$ \\
\hline $\begin{array}{l}\text { Scientific } \\
\text { methods }\end{array}$ & $\begin{array}{l}\text { Understanding of } \\
\text { Nature of scientific } \\
\text { research, Experiment, } \\
\text { Probability }\end{array}$ & $\begin{array}{l}3 \text { multiple choice items on Nature of scientific } \\
\text { study, Experiment, Probability }\end{array}$ & $\begin{array}{l}\text { In the following four options, which } \\
\text { is the right explanation for } \\
\text { 'comparison experiment'? }\end{array}$ \\
\hline \multirow{2}{*}{$\begin{array}{l}\text { Attitude } \\
\text { toward science }\end{array}$} & $\begin{array}{l}\text { Rejection of } \\
\text { superstition as } \\
\text { scientific attitude } \\
\end{array}$ & $\begin{array}{l}3 \text { five-point scale items on Astrology, Fortune } \\
\text { telling sticks, Dream interpretation }\end{array}$ & $\begin{array}{l}\text { How much do you trust the Fortune } \\
\text { telling sticks? }\end{array}$ \\
\hline & $\begin{array}{l}\text { Engagement with } \\
\text { public scientific affairs }\end{array}$ & $\begin{array}{l}3 \text { five-point Likert scale items on Paying attention } \\
\text { individually, Talking with relatives and friends, } \\
\text { Participation actively }\end{array}$ & $\begin{array}{l}\text { How often do you talk with relatives } \\
\text { and friends about public scientific } \\
\text { affairs? }\end{array}$ \\
\hline
\end{tabular}

Two experts reviewed the content to ensure the validity of the instrument. Both reviewers were full professors for science education program in top-tier universities in China. The questionnaire was revised for five times with feedback and suggestions from the two reviewers incorporated before it was finalized. Eleven students from different disciplines pilot test the questionnaire items to eliminate ambiguity. The Cronbach's alpha value for test reliability was 0.81 . Table 2 lists the main constructs and the categories of the items in the instrument.

To examine possible factors that might influence the level of scientific literacy, descriptive items were used to collect background information in this questionnaire. There were two different kinds of factors, one was demographic factors and the other were new media use factors. Three demographic items (i.e., region, major or area of study, and gender) were noted. For new media use factor, one multiple choice item was used to document the media through which students obtained scientific information, through which user vs non-user of new media was broken down. Additionally, two multiple choice items on scientific information identification when reading and sharing from new media were included. A scale of " 1 " to " 4 " was used for these two items, whereas " 1 " stands for "Not concern about identification," "2" stands for "Not deliberately identify," "3" stands for "Identify based on common sense," and " 4 " stands for "Identify based on scientific knowledge."

For the influence of science-oriented new media use on scientific literacy, independent t-test, correlation analysis and hierarchical multiple regression were used to explain the differences in scientific literacy between science-oriented new media users and non-users, relationship between identification ability and scientific literacy, and effect of students' background and new media use factors on their scientific literacy.

\section{Participants}

A sample of 2,062 undergraduate students from ten universities in the Shanghai participated in this investigation. As one of the most developed metropolises in China, Shanghai has accommodated people from across the country. Moreover, these university students reflect the current generation who have grown up with new media.

Moreover, the sampling was designed by considering the distribution of the diversified dispositions of the students in terms of scientific knowledge. In particular, a stratified sampling method was used in this research to encompass equal proportions of students with different majors. Among the ten universities sampled, two were comprehensive universities, three were science and engineering universities, three were social science universities, and two were liberal arts universities. The questionnaire was anonymous and self-administered. The valid response rate was $91.0 \%(1,870$ out of 2,062$)$. The education levels of the participants were undergraduate students $(79.8 \%)$ and graduate students (20.2\%). Age ranged from 18 to 35 , with $58.58 \%$ from 18 to $22,38.31 \%$ from 22 to $25,3.11 \%$ from 26 and above. There was a total of 1,025 males (54.8\%) and 845 females (45.2\%) students in this study. In terms of participants' major, $35.4 \%$ of them were majored in science, $33.2 \%$ in social science, and $31.4 \%$ in liberal arts. The regional (hometown) distribution was $44.7 \%$ from east China, $32.9 \%$ from central China, and $22.5 \%$ from west China. The dissection of region was from the economic development perspective indicated by National Bureau of Statistics of China (2017), the east was the most developed, followed by the central, and the west (National Bureau of Statistics of China, 2011). 
Table 3. Distribution of number of comments

\begin{tabular}{cc}
\hline Average comment number for each article & Number of websites \\
\hline $1-10$ & 15 \\
\hline $10-20$ & 4 \\
\hline $20-30$ & 2 \\
\hline $30-$ & 1 \\
\hline
\end{tabular}

\section{FINDINGS}

\section{Quality of Science-oriented New Media}

\section{Quality of science-oriented websites}

This study selected 42 websites as samples of scientific new media. Among them, $93 \%$ targeted adults as their primary audience, whereas $7 \%$ targeted children. The targeted users of the most websites 30 of 42 the sampled websites) were individuals, whereas the remaining 12 targeted special interest groups such as academic group. Moreover, $55 \%$ of the sampled websites were non-profit, whereas about half of which were supported by government or educational institutions.

Most of the sampled science websites had a wide content coverage. In particular, $81 \%$ of the sampled websites covered various science contents in general, whereas only $19 \%$ focused on domain-specific scientific knowledge. For example, China New Energy, one sampled website, published content strictly related to the development of energy. With regard to the depth of scientific knowledge, $74 \%$ of the sampled websites provided a detailed explanation of their published content, whereas $19 \%$ offered simple descriptions. Only $7 \%$ of the sampled websites provided expansions with further professional academic discussions, which indicate in-depth analyses and discussions rarely seen. From these results, it could be inferred that most websites were designed to promote understanding of general scientific knowledge for the general public. However, there were fewer websites offering the specific scientific knowledge for a special group of people. Most of the sampled websites provided detailed explanations for the scientific information, but those that offered expansions such as using references were still limited.

Accuracy, authority, regular updating, and content uniqueness were the main indicators used to evaluate the "science content issues" of those sampled websites. For the accuracy of the science content, $60 \%$ of the websites failed to indicate the sources of information and the authors of scientific essays. Among the websites that indicate authorship, only eight contained information that identified the authors who had sufficient expertise required to write their pieces. The review mechanism of $90 \%$ of the websites was not transparent, which indicated that the acceptance criteria or process of the published essays could not be found from these websites. Accordingly, there are much to improve in content accuracy. Notably, all the websites did not contain notes on personal bias, political affiliation, religious affiliation, or advertisements. For the authority of the science content, $50 \%$ of the owners of the websites have certified academic background. In addition, $26 \%$ of the websites provided information that allows the readers to contact the authors and address credibility, authenticity, and legality issues of published pieces. For the updating rate to keep content current, only two websites did not update regularly. For content uniqueness, $74 \%$ of the sampled websites had original articles that were exclusively published on the websites and could not be found elsewhere. Generally speaking, most websites performed well for authority, update and uniqueness.

For the workability dimension, $93 \%$ of the sampled websites were easy to browse, with a user-friendly interface design and concise page layout. In other words, the interface was designed with obvious navigation and menu, and users could browse easily. Moreover, $76 \%$ of the sampled websites added illustrations or pictures to make their content legible and accessible, and $88 \%$ provided a search function. The analysis of website links showed that $76 \%$ of the sampled websites had links to other online sources including a few links led to advertisements or other unrelated contents.

The interactivity of the sampled websites was assessed mainly based on the quantity of user comments. A total of 22 websites provided a comment section to boost user engagement. Table 3 shows that 15 websites receive an average of one to 10 comments for each article. Only one website got over 30 comments for each article.

\section{Quality of science-oriented microblogs}

A total of 20 science-oriented microblogs were sampled, coded, and analyzed. All these microblogs targeted the general public and were non-profit. The owners of ten microblogs were either authoritative scientific research departments or government agencies. 
Table 4. Frequency distribution of scientific literacy scores

\begin{tabular}{llccc}
\hline & & Frequency & Percent & Cumulative Percent \\
\hline \multirow{4}{*}{ Valid } & Poor (0-60) & 35 & 1.9 & 1.9 \\
\cline { 2 - 5 } & Fair (60-70) & 513 & 27.4 & 29.3 \\
\cline { 2 - 5 } & Good (70-80) & 1128 & 60.3 & 89.6 \\
\cline { 2 - 5 } & Very Good (80-90) & 109 & 5.8 & 95.5 \\
\cline { 2 - 5 } & Excellent (90-100) & 85 & 4.5 & 100.0 \\
\hline \multicolumn{2}{l}{ Total } & 1870 & 100.0 & \\
\hline
\end{tabular}

In terms of scientific knowledge scope, 13 microblogs covered comprehensive scientific information, such as Science Squirrels Club. The remaining 7 microblogs were aimed at specific areas. For example, China Weather Station posts scientific information related to meteorology. For the content depth, 14 microblogs provided detailed explanations to the topics under the discussions, whereas 6 provided only brief descriptions. None of the microblogs presented further analyses or discussions from academic perspectives.

The quality of the science content in those sampled microblogs was also assessed. For accuracy, $10 \%$ of the microblogs did not provide information source and $65 \%$ did not have rules to verify content. More than $50 \%$ of the microblogs frequently published conference advertisements and personal emotional status. The authority level of the microblogs was also evaluated. The owners of two sampled microblogs had a certified academic credentials. Most scientific knowledge on the Science Squirrels Club microblog was provided by subject matter experts. Meanwhile, $70 \%$ of the sampled microblogs always repost information from other famous websites, which degrades their individual uniqueness.

For the interactivity of the sampled microblogs, eight had less than 10,000 followers, five had 10,000 to 50,000 followers, two had 50,000 to 100,000 followers, and two had over 500,000 followers. The Science Squirrels Club, which was the most popular blog among the sampled ones, attracted approximately 1,630,000 followers. The number of article comments was another factor in this study. The popular microblogs such as the Science Squirrels Club and Curious Doctor had an average of over 100 comments per article. However, 14 microblogs had nearly no comment at all at the time of this study.

\section{Relationship between Scientific Literacy and Science-oriented New Media}

\section{Scientific literacy level of the sampled students}

The general level of the scientific literacy of the sampled students is provided in Table 4 . The students had a mean score of $73.28(\mathrm{SD}=6.92$, median $=72.88)$. The majority of the students $(60.3 \%)$ scored within the range of 70 to 80 , followed by $27.4 \%$ scoring between 60 and 70 . Approximately $10 \%$ scored higher than 80 , with $5.8 \%$ scoring within the range of 80 to 90 and $4.5 \%$ scoring within the range of 90 to 100 . Only $1.9 \%$ of the students scored lower than 60 . From the results, most of the students had mid-range scores, but only a few could achieve an excellent level.

The scores for the basic scientific knowledge of the students were analyzed. In terms of their understanding of scientific concepts, the students scored an average of $2.23(\mathrm{SD}=0.97)$ out of 4 (correct rate: $55.75 \%)$. In terms of their understanding of scientific viewpoints, the students scored an average of $6.77(\mathrm{SD}=1.53$ ) out of 10 (correct rate: $67.70 \%$ ). Similar results were found for the level of scientific methods, with the students scoring an average of 1.93 $(\mathrm{SD}=0.59$ ) out of 3 (correct rate: $64.33 \%$ ). The measured level of attitude toward science was moderate. Cumulative percentages of 5 "strongly disagree" and 4 "disagree" were obtained for astrology, fortune telling sticks, and dream interpretation $(36.4 \%, 68.4 \%$, and $62.6 \%$ respectively). Cumulative percentages of 5 "very often" and 4 "often" were obtained for individually paying attention, talking with relatives and friends, and participating actively $(69.1 \%$, $44.9 \%$, and $36.4 \%$, respectively).

Among the background variables collected from the demographic information of the students, an independent $t$-test showed that no significant difference was found on the level of scientific literacy with regard to gender [ $t$ $(1867)=1.634, p=0.103]$. By contrast, a significant difference was observed among different education levels [ $t$ $(1867)=-11.382, p=0.000]$. The mean score of graduate students was 76.78, whereas that of undergraduate students was 72.40. An ANOVA analysis determined that students' major (i.e., area of study) made a significant difference on scientific literacy level, whereas geographic region did not. A significant difference was found at the $\mathrm{p}<0.05$ level for three different majors, as noted in Table 5 [F $(2,1867)=5.67, \mathrm{p}=0.004]$. Post hoc analysis indicated that the mean score of science major students $(\mathrm{M}=73.63, \mathrm{SD}=7.43)$ was significantly higher than those of social science major students $(\mathrm{M}=72.76, \mathrm{SD}=5.62)$ and art major students $(\mathrm{M}=71.33, \mathrm{SD}=7.30)$. 
Table 5. Students' scientific literacy score against variables of region and major

\begin{tabular}{lcccc}
\hline & M & SD & F (2, 1867) & P \\
\hline Different Regions & & & 2.33 & .097 \\
\hline East China & 72.90 & 7.36 & & \\
\hline Central China & 73.53 & 6.63 & & \\
\hline West China & 72.90 & 6.89 & 5.67 & \\
\hline Different Majors & & & & \\
\hline Science major & 73.63 & 7.43 & \\
\hline Social major & 72.76 & 5.62 & \\
\hline Art major & 71.33 & 7.30 & \\
\hline${ }^{*} p<.05$ & & &
\end{tabular}

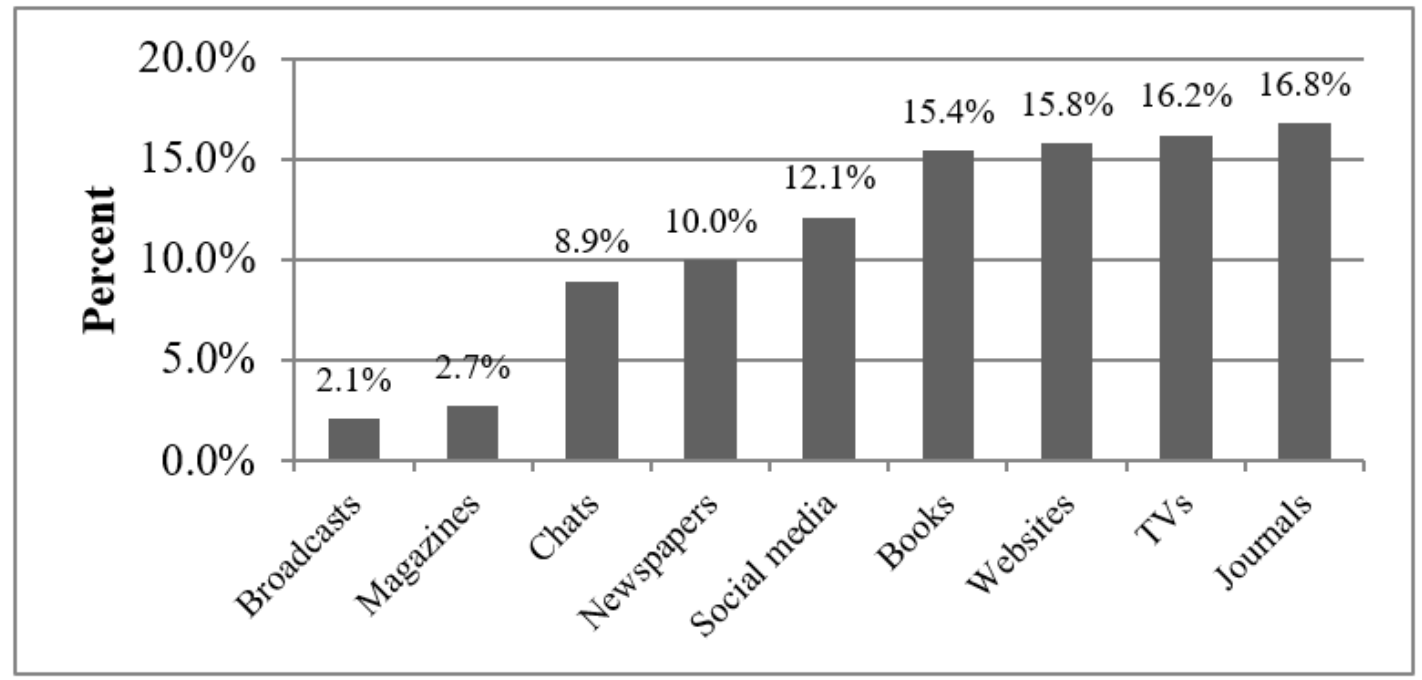

Figure 1. Distribution of channels used for scientific information

\section{Feature of students' science-oriented new media use}

Figure 1 shows the breakdown of nine scientific information channels. Among these channels, social media $(12.1 \%)$ and websites $(15.8 \%)$, which are typical new media, overtook newspapers $(10.0 \%)$, chats $(8.9 \%)$, magazines $(2.7 \%)$, and broadcasts $(2.7 \%)$. These new media have successfully penetrated the mainstream media channels. Social media ranked in the middle of the distribution. Websites, followed by traditional TV channels (16.2\%) and journals $(16.8 \%)$, which had an information gatekeeper, were ranked as the top three. In all, students commonly choose different channels to access scientific knowledge, and they frequently use various new media in their daily lives.

For students' ability to identify scientific information on science-oriented new media, the analysis result showed that when students attempted to identify scientific information, they tended to rely more on their common sense rather than using critical evaluation of scientific knowledge. When students read information (i.e., the reading situation), the percentages of "identify information by common sense" and "identify information by scientific knowledge" were $37.1 \%$ and $20.3 \%$, respectively. When they choose to share information with friends (i.e., the sharing situation), the percentages of "identify information by common sense" and "identify information by scientific knowledge" were $27.9 \%$ and $15.4 \%$ respectively.

\section{Influence of science-oriented new media use on scientific literacy}

To investigate the influence of science-oriented new media use on scientific literacy, this section conducted three analysis: (1) differences in scientific literacy between science-oriented new media users and non-users, (2) correlation between identification ability for information from science-oriented new media and scientific literacy, and (3) effect of science-oriented new media use, together with students' background variables, on their scientific literacy.

An independent T-test was conducted to compare the scientific literacy levels between users and non-users of new media. As shown in Table 6, the result indicated that the channel variables made a significant difference on 
Table 6. Result of independent T-test for scientific literacy scores by against use of new media

\begin{tabular}{|c|c|c|c|c|c|c|c|}
\hline & \multicolumn{2}{|c|}{ Users } & \multicolumn{2}{|c|}{ Non-users } & \multirow{2}{*}{$\boldsymbol{t}$} & \multirow{2}{*}{$d f$} & \multirow{2}{*}{$\boldsymbol{P}$} \\
\hline & $\mathbf{M}$ & SD & $\mathbf{M}$ & SD & & & \\
\hline Websites & 74.12 & 7.66 & 72.57 & 6.14 & 4.75 & 1643.34 & $.000^{* * *}$ \\
\hline Microblogs & 73.00 & 5.92 & 73.42 & 7.36 & -1.34 & 1490.67 & .179 \\
\hline
\end{tabular}

Table 7. Correlation between students' ability of information identification and level of scientific literacy

\begin{tabular}{lccc}
\hline Variables & $\mathbf{1}$ & $\mathbf{2}$ & $\mathbf{3}$ \\
\hline 1 (Identification ability in reading) & - & $.45^{* *}$ & $.53^{* *}$ \\
\hline 2 (Identification ability in sharing) & & - & $.56^{* *}$ \\
\hline 3 (Scientific literacy score) & & - \\
${ }^{* *}$. Correlation is significant at the 0.01 level (2-tailed) & &
\end{tabular}

Table 8. Model summary for variables that influence scientific literacy

\begin{tabular}{|c|c|c|c|}
\hline Predictor Variables & $\beta$ & $\Delta \mathbf{R}^{2}$ & $\mathbf{R}^{2}$ \\
\hline Block 1(Background variables) & & $.31^{* *}$ & $.31^{\star \star}$ \\
\hline 1 (Gender) & 7.22 & & \\
\hline 2 (Region) & 5.31 & & \\
\hline 3 (Education) & $10.32^{\text {** }}$ & & \\
\hline 4 (Major) & $13.91^{* *}$ & & \\
\hline Block 2 (New media variables) & & $.23^{* *}$ & $.54^{* *}$ \\
\hline 1 (Using science-oriented new media or not) & 5.63 & & \\
\hline 2 (Identification ability in reading) & $7.83^{* \star}$ & & \\
\hline 3 (Identification ability in sharing) & $7.96^{* \star}$ & & \\
\hline
\end{tabular}

the level of scientific literacy $[t(1643.34)=4.75, \mathrm{p}=0.000)]$ given that website users scored significantly higher than non-users. Nevertheless, the use of social media like microblogs did not make any difference on the level of scientific literacy $[t(1490.67)=-1.34, \mathrm{p}=0.179)]$.

A correlation analysis was conducted to investigate the relationship between students' ability to identify scientific information critically and their scientific literacy. The result, which is presented in Table 7, found a significant correlation between these two variables.

It should be noted that scientific literacy could be influenced by different factors. In this study, two types of factors were contained: the background variables (gender, region, education level, major) and new media variables (using science-oriented new media or not, identification ability in reading or sharing). To further examine the contributions of the two type of factors to scientific literacy, hierarchical multiple regression was used, with the scientific literacy as dependent variable, and background factors and new media factors entered equation as block 1 and block 2 respectively. Nominal variables had been changed to dummy ones before entering the equation.

Table 8 shows the model summary for the equation. It could be seen that both the block $1\left(\Delta \mathrm{R}^{2}=.31\right)$ and block $2\left(\Delta \mathrm{R}^{2}=.23\right)$ influenced scientific literacy, which meant that background variables could explain $31 \%$ of the difference in scientific literacy, and new media variables influence the change in scientific literacy by $23 \%$. Together, these two types of factors contribute to scientific literacy by $54 \%$. In addition, the coefficient $\beta$ explained the prediction degree of each variable. It could be seen that the education $(\beta=10.32, p<.001)$ and major $(\beta=13.91, p<$ $.01)$ in block 1 predicted scientific literacy significantly. Two variables in block 2 predicted scientific literacy at .01 significant level, with coefficient $\beta$ equaled to 7.83 and 7.96 for identification ability in reading and sharing respectively.

\section{DISCUSSION}

This study was to explore the impact of new media on the scientific literacy of college students in Shanghai, China by examining the quality of science-oriented new media and the scientific literacy levels of those college students. Although limitations result from sampling college students as representatives of the general public, considering that college students are the typical avid users of new media, generalizing the findings, if any, to indicate any impact that social media may have on the scientific literacy level of the general public, is rational. However, given that the purpose of this investigation is to identify factors that may influence the scientific literacy level of the public instead of describing literacy level, the various backgrounds of the sampled college students, 
including their regions of origin, majors, and main sources of scientific information, can be acceptably used as an approximation of the intended general public.

The current study analyzed the two types of science-oriented new media from multiple perspectives. These new media have common features in terms of target users, scientific knowledge coverage, management, and influence. Both types of media target the general public. The scientific information published on these new media is mostly non-domain-specific, which indicates that they aim to distribute common information to a wide-ranging audience. These findings echo with Wenninger, Weingart, and Wormer, (2017), indicating that the science-oriented new media helps the science knowledge dissemination to general audience. Moreover, our research reveals the depth of scientific information on new media is moderate. Most science-oriented websites and microblogs provide explanations of published scientific knowledge, which may help the general public understand previously unassimilated and obscure scientific knowledge to a certain degree. This result is consisted with Lievrouw (2010), which indicates that science-oriented new media provides certain scientific knowledge explanations for public involvement.

The analyses of science-oriented websites and microblogs revealed that these new media were more frequently used as scientific information channels than traditional media outlets, such as magazines and newspapers. In particular, science-oriented websites were used more than microblogs. Further analysis indicated that students who obtained scientific knowledge from websites had significantly higher scientific literacy levels than those who did not. By contrast, the use of microblogs did not produce a statistically significant difference on the scientific literacy level of students. This result is in line with the findings by Fauville et al. (2015), who asserted that easy access to social media had developed personal interest in science, but it did not ensure improvement in the scientific literacy of citizens by simply posting information. Our evaluation of new media provides an explanation of this issue. As important sources of scientific media, half of the evaluated websites are created by organizations with solid expertise and academic background, which indicates the scientific information on those media was provided by eligible providers of scientific information. However, the providers of microblogs rarely exhibit a solid academic background. The resources used on microblogs are frequently mixed with "messy" information, which to certain extents, aggravate the damage on the scientific credibility of microblogs. Given that the "claimed" scientific content published on new media has been typically regarded as less credible than that of traditional media, identifying and extracting legitimate information by using a critical thinking remains an insurmountable challenge among novice readers.

This study shows that the students' engagement in science-oriented new media remains limited. Although the majority of science-oriented websites and microblogs incorporate online discussions for comments and messages, only a few people actually participate in them. Similarly, as noted by Fauville et al. (2015), even Facebook, the iconic social media platform with a widely used social networking service, offers few opportunities for followers to develop their scientific literacy through social participation on the Facebook page of an organization.

As the findings indicate, the majority of the sampled students achieved medium scientific literacy level (i.e., a score between 70 and 80 ). In terms of basic scientific constructs and methods, their performance was even lower at a correct response rate between $55 \%$ and $70 \%$. To understand what this rate mean, this result was compared with the results of the longitudinal research conducted by Impey (2013) and Impey, Formanek, Buxner and Wenger (2017), which showed that US college students had higher performances on scientific knowledge, with $80 \%$ correct rate in 2008 and $79 \%$ in 2015. In terms of scientific attitude, the level was generally considerably lower than those of the other constructs, with less than $40 \%$ of the students disagreeing that astrology is scientific, while a similarly weighted result was found among US students (Impey, 2013; Impey et al., 2017). The lowest section scored was the critical thinking level, as reflected by the fact that only an extremely small segment of the sampled population actively participated in public scientific affairs. Students could not rationally apply scientific knowledge to a field, such as astrology, as Lindeman and Aarnio (2007) suggested. This study finally found that the identification ability, together with education and major, could predict scientific literacy level.

These findings together with previously published ones deepen and enrich the knowledge of the impact of science-oriented new media on the scientific literacy levels of college students and the general public. This study sheds light on the strategic aspects of science education instruction and the design of science-oriented new media.

First, to take advantage of new media in developing scientific literacy, it is necessary to provide guidance on how to use these new media. As most new media do not contain transparent review mechanism, this study suggests that science educators recommend reliable new media resource to students. From the result of hierarchical multiple regression, the identification ability is predictable for scientific literacy. According to this, another important suggestion is to teach students how to evaluate different sources with critical eyes. Those dimensions in the coding scheme as Table 1 shows could be used as reference tools in those evaluations. For example, it is useful to check the website owner's identity to make pre-evaluation. In addition, as the engagement for discussion in both websites and social media is not that active and strong, educators should help to initiate some discussions and comments online to promote learning through new media. Extending the reach of science was also suggested by Warden 
(2010), who indicated that the virtually unlimited space offered by the Internet could be used to elaborate exploratory processes over time, rather than simply display results. To this point, Fauville et al. (2015) also provide the posting strategies such as the types of posting content, the number of words composed in a post, and posting frequency.

Second, as the number of scientific information sources for the public grows rapidly, the credibility of new media becomes more important. We need to work to prevent distorted, and faked online science information. To sum up, social media (like microblog) has much more rooms for improvement than those of the websites. Internet services, such as social networks and web portals, offer timely and updated information that helps students stay current with the latest scientific discoveries. The operators of science-oriented social media should encourage and invite more writers with diverse academic backgrounds to join in disseminating their scientific knowledge. A strict and rigorous review mechanism should also be established to ensure the credibility and reliability of published information. Not all college students have the ability to accurately determine the authenticity of information, an gatekeeping by the content provider would help the situation.

\section{CONCLUSION}

This study examined the quality of science-oriented new media and measured the scientific literacy level of Chinese college students. Consequently, the impact of new media on communicating scientific information was investigated. This study found that new media have been used as important channels by college students to gain scientific knowledge. However, the quality of new media varies and the considerable improvements required to expand the impact of new media to science communication as major channels still exist. Moreover, particular attention should be directed toward the credibility of scientific content sources.

The examination of the scientific literacy level of college students indicated that the focus should be directed toward the ability to identify credible scientific information and interactive participation from educational perspectives. Instructional intervention should be considered to provide guidance in selecting credible science learning resources and to offer training on developing the critical thinking skills of students.

This study is limited because it focused only on the preferences of college students and their inherent affinity toward new media. Future studies need to investigate detail pertinent processes, such as how students engage in science learning using new media, how their science knowledge and experiences change over time, and how critical thinking skills can be developed to obtain scientific knowledge.

\section{REFERENCES}

American Association for the Advancement of Science. (1993). Benchmarks for Science Literacy. New York: Oxford University Press.

American Association for the Advancement of Science. (2016). Communicating Science Online. Retrieved from https://www.aaas.org/programs/center-public-engagement-science-and-technology/communicatingscience-online

Anderson, A. A., Brossard, D., Scheufele, D. A., Xenos, M. A., \& Ladwig, P. (2014). The "nasty effect:" online incivility and risk perceptions of emerging technologies. Journal of Computer-Mediated Communication, 19(3), 373-387. https:/ / doi.org/10.1111/jcc4.12009

Aral, S., \& Walker, D. (2012). Identifying influential and susceptible members of social networks. Science, 336(6092), 337-341. https:// doi.org/10.1126/science.1215842

Bauer, M. W. (2009). The evolution of public understanding of science-discourse and comparative evidence. Science, Technology and Society, 14(2), 221-240. https:// doi.org/10.1177/097172180901400202

Brossard, D. (2012). A (brave) new world: Challenges and opportunities for communicating about biotechnology in new information environments. In M.-D. Weitze, A. Pühler, W. M. Heckl, B. Müller-Röber, O. Renn, P. Weingart, \& G. Wess (Eds), Biotechnologie-Kommunikation (pp. 427-445). Heidelberg: Springer.

Brossard, D. (2013). New media landscapes and the science information consumer. Proceedings of the National Academy of Sciences, 110(3), 14096-14101. https:/ / doi.org/10.1073/pnas.1212744110

Brossard, D., \& Scheufele, D. A. (2013). Science, new media, and the public. Science, 339(6115), 40-41. https:// doi.org/10.1126/science.1232329

Brossard, D., \& Shanahan, J. (2006). Do they know what they read? Building a scientific literacy measurement instrument based on science media coverage. Science Communication, 28(1), 47-63. https:/ / doi.org/10.1177/1075547006291345 
Buxner, S., Impey, C., Romine, J., \& Nieberding, M. (2015). Investigating knowledge and sources of scientific information of university students and lifelong learners. Retrieved from https://www.iau.org/static/science/ scientific_bodies/divisions/c/2015/dc_sanlyn_buxner_educationii.pdf

Fauville, G., Dupont, S., von Thun, S., \& Lundin, J. (2015). Can Facebook be used to increase scientific literacy? A case study of the Monterey Bay Aquarium Research Institute Facebook page and ocean literacy. Computers E Education, 82, 60-73. https:/ / doi.org/10.1016/j.compedu.2014.11.003

Fives, H., Huebner, W., Birnbaum, A. S., \& Nicolich, M. (2014). Developing a measure of scientific literacy for middle school students. Science Education, 98(4), 549-580. https:/ / doi.org/10.1002/ sce.21115

Gauld, C. (1982). The scientific attitude and science education: A critical reappraisal. Science Education, 66(1), 109121. https:// doi.org/10.1002/sce.3730660113

Hanushek, E., \& Woessman, L. (2016). Knowledge capital, growth, and the East Asian miracle. Science, 351(6271), 344-345. https:/ / doi.org/10.1126/science.aad7796

Harris, R. (2007). Evaluating Internet research sources. Retrieved from http:/ / www.virtualsalt.com/evalu8it.com

Impey, C. (2013). Science literacy of undergraduates in the United States. In A. Heck (Ed.), Organizations, People and Strategies in Astronomy (pp. 353-364). Heidelberg: Springer.

Impey, C., Buxner, S., Antonellis, J., Johnson, E., \& King, C. (2011). A twenty-year survey of science literacy among college undergraduates. Journal of College Science Teaching, 40(4), 31-37. Retrieved from https:/ / www.depauw.edu/files/resources/impey2011.pdf

Jarman, R., \& McClune, B. (2007). Developing scientific literacy: Using news media in the classroom. Maidenhead, England: Open University Press.

Laberge, Y. (2016). New media and social networks. Public Understanding of Science, 25(8), 1017-1019. https:/ / doi.org/10.1177/0963662515619543

Laugksch, R. C. (2000). Scientific literacy: A conceptual overview. Science Education, 84(1), 71-94. https:// doi.org/10.1002/(SICI)1098-237X(200001)84:1<71::AID-SCE6>3.0.CO;2-C

Liang, X., Su, L. Y.-F., Yeo, S. K., Scheufele, D. A., Brossard, D., Xenos, M.,Corley, E. A. (2014). Building Buzz: (Scientists) Communicating science in new media environments. Journalism \& Mass Communication Quarterly, 91(4), 772-791. https://doi.org/10.1177/1077699014550092

Lievrouw, L. A. (2010). Social Media and the Production of Knowledge: A Return to Little Science?. Social Epistemology, 24(3), 219-237. https:/ / doi.org/10.1080/02691728.2010.499177

Lindeman, M., \& Aarnio, K. (2007). Superstitious, magical, and paranormal beliefs: An integrative model. Journal of Research in Personality, 41(4), 731-744. https:/ / doi.org/10.1016/j.jrp.2006.06.009

Miller, J. D. (1983). Scientific literacy: A conceptual and empirical review. Daedalus, 112(2), 29-48. Retrieved from http:/ / www.jstor.org.ezproxy.neu.edu/stable/20024852

Miller, J. D. (2004). Public understanding of, and attitudes toward, scientific research: What we know and what we need to know. Public Understanding of Science, 13(3), 273-294. https:/ / doi.org/10.1177/0963662504044908

National Bureau of Statistics of China. (2011). Bulletin of the sixth national population census in 2010. Retrieved from http:/ / www.stats.gov.cn/tjsj/tjgb/rkpcgb/qgrkpcgb/201104/t20110429_30328.html

National Bureau of Statistics of China. (2017). China Statistical Yearbook 2017. Retrieved from http://www.stats.gov.cn/tjsj/ndsj/2017/indexch.htm

National Research Council. (1996). National Science Education Standards. Washington, DC: National Academy Press.

National Science Board. (2014). Science and engineering indicators: 2014 . Retrieved from https:// www.nsf.gov/statistics/seind14/content/etc/nsb1401.pdf

National Science Board. (2016). Science and engineering indicators: 2016. Retrieved from https://www.nsf.gov/nsb/publications/2016/nsb20161.pdf

Nisbet, M. C., Scheufele, D. A., Shanahan, J., Moy, P., Brossard, D., \& Lewenstein, B. V. (2002). Knowledge, reservations, or promise? A media effects model for public perceptions of science and technology. Communication Research, 29(5), 584-608. https:/ / doi.org/10.1177/009365002236196

North Carolina State University's Science Education Research in Visual Instructional Technologies Group. (1999). Evaluating Science $\quad$ RWW $\quad$ Resources. Retrieved https://www.ncsu.edu/meridian/jul99/coastal/coastalappendix.html

Pariser, E. (2012). The Filter Bubble: How the New Personalized Web Is Changing What We Read and How We Think. New York: The Penguin press. https://doi.org/10.3139/9783446431164 
Peters, H. P., Dunwoody, S., Allgaier, J., Lo, Y.-Y., \& Brossard, D. (2014). Public communication of science 2.0. Embo Reports, 15(7), 749-753. https:/ / doi.org/10.15252/embr.201438979

Rennie, L. (2005). Science awareness and scientific literacy. Teaching Science: The Journal of the Australian Science Teachers Association, 51(1), 10-14. Retrieved from http:// search.ebscohost.com.ezproxy.neu.edu/login.aspx

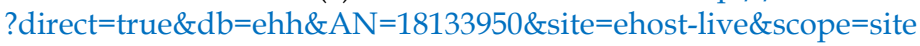

Rubba, P. A., \& Andersen, H. O. (1978). Development of an instrument to assess secondary school students understanding of the nature of scientific knowledge. Science Education, 62(4), 449-458. https:/ / doi.org/10.1002/sce.3730620404

Rundgren, C.-J., Rundgren, S.-N. C., Tseng, Y.-H., Lin, P.-L., \& Chang, C.-Y. (2012). Are you SLiM? Developing an instrument for civic scientific literacy measurement (SLiM) based on media coverage. Public Understanding of Science, 21(6), 759-773. https:/ / doi.org/10.1177/0963662510377562

Smith, A. G. (1997). Testing the surf: criteria for evaluating Internet information resources. The Public AccessComputer Systems Review, 8(3), 5-23. Retrieved from https://journals.tdl.org/pacsr/index.php/pacsr/ article/view/6016/5645

State Council of the People's Republic of China. (2006). The Outline of the Action Plan for Improving Scientific Literacy for All. Beijing: The People Press.

Thomas, G., \& Durant, J. (1987). Why should we promote the public understanding of science? In M. Shortland (Ed.), Scientific literacy papers (pp. 1-14). Oxford: Rewley House.

Warden, R. (2010). The Internet and science communication: Blurring the boundaries. Ecancermedicalscience, 4(203), 203-221. https:// doi.org/10.3332/ ecancer.2010.203

Wenninger, A., Weingart, P., \& Wormer, H. (2017). Social media and digital science communication: Analysis and recommendations for dealing with risks and opportunities in a democracy. Retrieved from https://www.acatech.de/wp-content/uploads/2018/03/WOM2_EN_web_final.pdf

Zimmerman, C., Bisanz, G. L., Bisanz, J., Klein, J. S., \& Klein, P. (2001). Science at the supermarket: A comparison of what appears in the popular press, experts' advice to readers, and what students want to know. Public Understanding of Science, 10(1), 37-58. https://doi.org/10.3109/a036854

\section{http://www.ejmste.com}

